\title{
Expresión de habilidades comunicativas para el desarrollo del pensamiento en niños de 5 a 6 años con el método filosofía para niños
}

\author{
Helen Roxana Valverde Limbrick \\ Mónica Paola Vargas Mora² \\ Rosa María Hidalgo Chinchilla ${ }^{3}$ \\ Dagoberto Núñez Picado ${ }^{4}$
}

Aceptado: 05 de diciembre del 2014

\section{Resumen}

Esta es la síntesis de una iniciativa de investigación microetnográfica que dio seguimiento a una experiencia de Filosofía para Niños (FpN) desarrollada en un jardín de niños en San José, en el año 2010. Para su ejecución se realizó una dinámica interactiva entre la docente y el grupo investigador quien ofreció capacitación previa y durante el proceso a la educadora en lo que es Filosofía para niños. Con fin de incentivar el pensamiento filosófico del grupo se hace uso de las lecturas del libro Hospital de muñecos de la autora Ann Sharp. Material literario elaborado con este propósito específico. El artículo deja ver, cómo una docente capacitada en FpN orienta con intuición y creatividad al grupo preescolar que se transforma poco a poco en una verdadera comunidad de diálogo. Se ofrece mediante extractos de la trama de interacción entre dicha comunidad el estilo filosófico del grupo de preescolar que cada vez sorprendía más con sus aportes al grupo investigador. Es así como se observa el surgimiento de temas filosóficos con pensamiento crítico, creativo y ético, habilidades del pensamiento como también capacidad argumentativa, de interrogarse y generar pensamiento, todo esto derivado de la dinámica vital, acontecida durante las sesiones de FpN. La principal conclusión de este estudio se refiere a que el grupo de preescolar, mediante la guía de su docente capacitada ha demostrado convertir su entorno en una comunidad de
1. Universidad Estatal a Distancia, Costa Rica; hvalverde@uned.ac.cr

3. Universidad Estatal a Distancia, Costa Rica; rhidalgo@uned.ac.cr

4. Universidad Estatal a Distancia, Costa Rica; dnunez@uned.ac.cr 
diálogo donde genera pensamiento filosófico, entendido éste como dinámico y complejo en las dimensiones crítica, ética y creativa.

Palabras clave: Filosofía para niños, Comunidad de Diálogo, Comunicación, habilidades del pensamiento. a trainer teacher, can turn its environment into a community of dialogue that generates philosophical thought, understood as dynamic and complex in the critical, ethical and creative dimensions.

Key words: Philosophy for Children, Community Dialogue, Communication, Thinking Skills.

\section{INTRODUCCIÓN}

La dinámica del jardín de niños de carácter público, dentro del Estado costarricense, integra en su jornada diaria experiencias que combinan diversidad de lenguajes. Uno de esos momentos es el denominado Período de conversación, el cual suele ser un intercambio verbal, entre el grupo y el docente, sobre conocimientos y experiencias de cada integrante, sin embargo puede ocurrir que, por diversas razones, no se potencie suficientemente en el grupo infantil el espíritu investigativo.

Al aplicar un programa cooperativo de enseñanza-aprendizaje, como es el caso del proyecto Filosofía para Niños, se modifica la dinámica de relaciones de poder que tradicionalmente ocurre en las salas de clase. Este informe de investigación da muestra, en parte, de cómo se desarrolla un proyecto educativo que enriquece las habilidades de pensamiento, así como las capacidades de la convivencia de acuerdo con el principio, consistentemente aplicado, de las comunidades de diálogo (CdD).

El Programa Filosofía para Niños (FpN) se propone, entre otros objetivos, promover en las personas el poder de capacidad argumentativa. Este tipo de prácticas no ha sido común en las salas de clase costarricenses, por lo que el grupo investigador, inquieto por conocer su aplicación y reacciones en esta población, realizó la experiencia, cuyo informe retoma dos ejes, reflexionados en las sesiones de trabajo del equipo, como instrumentos filosóficos derivados de las transcripciones de interacciones entre integrantes del grupo. La experiencia se desarrolló en un grupo de Ciclo de Transición en Sabanilla de Montes de Oca.

El primer eje temático del análisis de la dinámica, desarrollada en la Comunidad de Diálogo, parte de las redes de interacción, que se producen en la sala de clase. El segundo eje, es el de los tópicos o temas filosóficos que se derivan de esa dinámica esencial de la CdD; a saber, la distinción filosófica entre hechos y valoraciones de hechos; entre emociones $y$ pensamiento; entre necesidades y estrategias y entre peticiones (estrategias) y exigencias.

Para entender qué dinámica caracteriza a una $\mathrm{CdD}$ en FpN no hay que concentrarse primero en los elementos temáticos, por esenciales que parezcan dentro de cierta lógica filosófica; lo determinante es el ambiente o estilos de aprendizaje de los grupos y cómo emergen los temas que se convierten en relevantes para los niños. Es así como la metodología de FpN practicada quiso explorar los frutos de justicia, verdad, bondad, que se procuran.

La Filosofía para niños apunta, en su modelo comunicacional, a indagar sobre las necesidades cognitivas y sociales de quienes participan en una comunidad de diálogo. Promueve, en la dinámica de la CdD, la distinción entre ideas y hechos observables; la responsable expresión de los sentimientos sin confundirlos con ideas; la invocación de las necesidades que están detrás de las emociones; y el planteamiento de estrategias para el hallazgo de satisfactores sinérgicos de las necesidades fundamentales. La dinámica de esas peticiones estratégicas se caracteriza por una honestidad suficientemente 
expresada mediante cierta dosis de empatía necesaria para la fluidez comunicativa.

La indagación filosófica, según FpN, tiene como objetivo último el desarrollo de un proceso comunicacional (CdD), en el cual, los asuntos filosóficos preparan para la atención, la escucha, la reflexión, etcétera, en procura de un pensamiento estéticamente cuidadoso (creativo), que tienda éticamente a la justicia (como factor valorativo) e incremente su madurez crítica conforme se aquilata en la toma de decisiones responsablemente asumidas.

Con el fin de reconocer lo que cada niño reali$\mathrm{za}$, en tanto ser humano que requiere estructurar su pensamiento, la FpN parte de lo expresado (lenguaje oral), pero a la vez destaca que no sólo lo dicho es importante, sino también el lenguaje corporal, que hay que entresacar de lo no dicho, de las acciones y situaciones comunicativas de la sala de clase, y por tal razón filosóficamente relevantes. Lo dicho por el docente tampoco se absolutiza, depende de la intuición y la creatividad pedagógica, es decir, del encuentro entre la dinámica del aprendizaje en relación con el régimen de enseñanzas, lo cual se consigue en términos de aprendizaje entre el docente y su grupo.

Las sesiones de Filosofía para Niños, en este caso, se desarrollaron con base en lecturas del libro denominado Hospital de los Muñecos, de la autora Ann Sharp; el cual fue creado, para estos propósitos y dirigidos a niños en edad preescolar.

Fueron factores fundamentales en el proceso de investigación la vocación, la intuición, la experiencia y el entusiasmo de Lorena (la docente quien se "matriculó" en el proyecto), dispuesta a recibir capacitación, analizar material específico de $\mathrm{FpN}$ y recibir a cuatro personas extrañas en la sala de clase, pese a las sorpresas que esto produjera en los niños durante la jornada pedagógica.

Para continuar con los hechos de la investigación, es importante aclarar que las temáticas en la $\mathrm{CdD}$ pueden ser similares a las que surgen en otros grupos de jardín de infantes. Lo que las hace diferentes es la habilidad que va desarrollando Lorena en el planteamiento de la pregunta filosófica, lo cual, a su vez, genera en el grupo habilidades de pensamiento que también favorecen la convivencia.

En el artículo se sintetiza la experiencia de investigación desde la metodología, las sesiones de trabajo y se brindan las conclusiones ante los resultados obtenidos.

\section{METODOLOGÍA}

Este es un estudio de tipo microetnográfico, que desde un enfoque cualitativo procura indagar los cambios experimentados en cuanto a habilidades de comunicación y pensamiento, en un grupo de Ciclo de Transición Grupo de preescolar de la Escuela José Figueres Ferrer, circuito 07, Dirección Regional de San José, Curso lectivo 2010. Al aplicar el método Filosofía para Niños, se cumple con el criterio de Hernández, Fernández y Baptista (2003), según el cual los estudios descriptivos buscan especificar las propiedades, las características y los perfiles, así como, evaluar datos acerca de distintos componentes o dimensiones del fenómeno que se está investigando.

El presente estudio se podría también incluir dentro de los "métodos orientados a solucionar problemas prácticos" o como una metodología orientada hacia el análisis de la dinámica de cambio en el aula, debido a que pretende implementar una acción específica en la práctica educativa del grupo de educación preescolar, "se refiere a una corriente de investigación cuyo objetivo es la obtención de conocimientos que puedan constituir una guía para la acción, una guía para sistematizar las razones de actuar de un modo u otro" (Bisquerra y Sabariego, 2004, 118).

La planificación en la dinámica de trabajo se caracterizó por un cronograma de reuniones, en las cuales, la docente intercambiaba su agenda temática y de trabajo con el grupo investigador, durante el año 2010, antes y después de las sesiones de FpN programadas. Durante las sesiones con la población infantil, el grupo investigador se dedicaba a observar y realizar grabaciones de audio y vídeo para, posteriormente, analizar junto con la educadora qué aspectos presentaba su planeamiento: en cada una 
de esas sesiones ella ensayaba con los niños actividades y preguntas filosóficas desde el proceso mismo de la CdD.

Los principios de la $\mathrm{CdD}$-según $\mathrm{FpN}$ - van siendo corroborados: La capacidad filosófica (habilidades de pensamiento y de sociabilidad), tanto de estudiantes como de la maestra, es ininterrumpida cuando el aula se vuelve un espacio pedagógico democrático en el que se plantean problemas, cuestionamientos éticos, visiones estéticas no convencionales y donde las preguntas epistemológicas básicas son reforzadas: por ejemplo, mediante la novela Hospital de Muñecos, la sala de clase se centró en discusiones sobre el nombre propio de cada niño, arribando a toda suerte de reflexiones filosóficas... ¿Alguien que no ha nacido tiene nombre?, ¿podría alguien equivocarse de mamá al nacer?, ¿cómo hacer para no equivocarse de mamá? Una muñeca sin nombre, ¿puede ponerse nombre ella sola? ¿Podría una persona cambiarse el nombre? Si uno no tuviera nombre, ¿cómo haría la mamá para llamarlo?, entre otras.

Con el fin de ir analizando la implementación de la $\mathrm{FpN}$, prestamos especial atención a las habilidades de comunicación y de pensamiento. Al agrupar lo observado y valorar sus principales vertientes, se buscó evidencia de las habilidades de comunicación y pensamiento de los niños mediante el uso y la formulación de preguntas que plantearon durante las actividades: justificaron puntos de vista, hicieron comparaciones, construyeron definiciones, fueron capaces de dar ejemplos y contraejemplos de lo que se estaba hablando, hicieron hipótesis, clasificaron y categorizaron la información, hicieron inferencias, utilizaron enunciados condicionales, escucharon diferentes puntos de vista ante un tema, fueron capaces de cuestionar las ideas de las demás personas del grupo y demostraron creatividad en las intervenciones.

De forma complementaria, en cuanto a las habilidades sociales durante las actividades, se valoró como muy importante el hecho del ejercicio de la escucha atenta, independientemente de quién sea la persona que está hablando (la maestra o los compañeros), la práctica de dirigirse a sus pares con respeto por sus opiniones, así como debatir dichas opiniones, sin incurrir en conflictos por temas o razones que están fuera de discusión, etc.

Al evaluar la metodología de trabajo, valoramos positivamente tres aspectos que se vieron fortalecidos en esta experiencia: la lectura grupal de los textos de FpN por parte del grupo investigador, las reuniones de la educadora con los investigadores para planificar y evaluar las sesiones con niños; y, finalmente, la creatividad práctica de la maestra al ir generando una $\mathrm{CdD}$ en la sala de clase. El insumo conceptual principal estribó en la lectura de fragmentos de una novela filosófica y después de cada práctica de lectura y diálogo de los niños, el equipo de investigación se reunía con la maestra para analizar detalladamente lo ocurrido y debatir sugerencias. La maestra planteó su evaluación general, al final del proceso: "...las sesiones me gustaron $y$ siento que es un trabajo que deja muchos frutos, en la última sesión ya habíamos encontrado la forma de explotar más el pensamiento de los niños, ver cómo iban estructurando las preguntas, cómo iban hablando algunos que nunca habian hablado."

\section{RESULTADOS}

\section{- Las sesiones de trabajo de FpN}

Para la puesta en práctica de la sistematización de la información, exploramos una técnica compuesta por dos facetas: primero dimos un título que reuniera los contenidos cognitivos de cada bloque de información transcrita, dicho título -definido por consenso y de acuerdo con el contenido de los fragmentos de las sesiones transcritas y analizadas -sirvió para iniciar cada análisis. Una segunda faceta fue comenzar la redacción del fragmento-transcrito, tal cual fue expresado por los niños, para que fuera parte del esquema general del texto o cuerpo del informe final.

Observe el lector una síntesis de cada sesión.

En la transcripción del audio se asignaba un símbolo diferente para niña o niño si, por el ruido de fondo, no era posible identificar el nombre de una o de otro. 
La primera sesión fue llamada "Un muñeco se ha perdido, ¿alguien sabe dónde está?”. La planeación de esta sesión partió de una actividad en la cual la maestra pidió que trajeran muñecos para contextualizar la lectura filosófica: la intención pedagógica era que, por medio de sus muñecos, los niños mostraran la diversidad de sus intereses. Así corrió la lectura:..."¿Tú tienes una muñeca? ¿Es una muñeca niño o una muñeca niña? Si tu tienes una muñeca, ¿por qué no la traes contigo la próxima vez? Así todos podremos platicar juntos y habrá el doble de personas en el grupo". (Sharp, 2004, p. 1)

En esta sesión, los juguetes fueron colocados juntos, para que posteriormente cada estudiante pasara a recoger el suyo; en ese contexto ocurrió un imprevisto: uno de los muñecos se extravió, el niño no lo hallaba. El siguiente es un breve extracto de las interlocuciones que se generaron en el grupo, a raíz de ese incidente:

¿Por qué creen que este muñeco se perdió?

-@ Porque era pequeñito

Maestra: ¿Qué otra posibilidad hay?

—\#: Porque tenía diferentes colores y se perdía con otras cosas.

Maestra: Muy bien, ¿por qué otra cosa puede ser que se hubiera perdido?

—\#: Porque es muy pequeñito.

—@: Era demasiado pequeñito y nadie lo podía ver.

El símbolo @ corresponde a la niña y el \# identifica a el niño.

Resuelto, provisionalmente el problema ocurrido, se retoma la lectura; se nota que la pregunta inicial para desarrollar la comunidad dialógica es formulada en términos muy generales, con el fin de que suscite otras preguntas o intervenciones directas:

Maestra: ¿Alguien sabe o quiere decir algo de lo que escuchamos?

Abigail: Hay muñecas diferentes, unas de plástico.

Maestra: Son de plástico, entonces estás describien-

do una muñeca ¿Cómo se podría describir más una muñeca? Fiorella

Fiorella: ${ }^{* *}$ Con cariño

Maestra: Con cariño

Fiorella: Sí, con abrazos, lo más importante es poder jugar ${ }^{* *}$
Para finalizar la sesión la docente continúa planteando preguntas para generar el diálogo:

Docente: ¿En qué podemos pensar la próxima vez? ¿En lo que nos diga el libro? (Los chicos movieron la cabeza diciendo sí) ¿ $\mathrm{U}$ otra cosa?

En la segunda sesión emergió el tema de "la desnudez: ¿es "algo" feo o solo una "mala" palabra?", como cuestionamiento de la CdD: la maestra abre la puerta de la discusión para que el alumnado se aventure en el ejercicio del pensamiento propio. La sesión lleva a que los niños se descubran pensando a partir de su propio cuerpo, su mente y sus manos. Ese es su punto de partida para pensar.

Y cuando se les confirma que lo que están haciendo es pensar, se aclara que son capaces de pensar y que el pensar es valioso porque supone que les ayuda a comprender mejor su vivencia cotidiana en la sala de clase.

La maestra inicia la lectura en voz alta:

"Antes yo pensaba que mi muñeca era una copia de un pequeño niño vivo, pero ya cambié de opinión. Algunos adultos tienen muñecas. ¿Sabías eso? Mi mamá me regaló mi muñeca cuando yo tenía dos años, ahora tengo cuatro.

¿Tú crees que mi muñeca tenga tres años?

Mi muñeca se llama Frida. Ese es el nombre que yo le puse. Cuando me la dieron no tenía nombre. Cuando yo nací tampoco tenía nombre.” (Sharp, 2004, p. 2)

Sorprende que el interés infantil tome otro curso pues el estímulo auditivo no resulta tan poderoso como el visual.

Las expectativas adultas se ven frustradas, la lectura que parecía tan interesante desde la perspectiva del grupo investigador no tuvo los resultados esperados. Es la portada del libro lo que les inquieta. Por su parte, la docente guía a la Comunidad de Diálogo:

—“Alexander, repítalo" pide la maestra.

-Alexander: Que Josué pensó con una chinga.

-Maestra: ¿Alguien me puede explicar para ver si entiendo el mensaje? 
-Maestra: Fabián usted sabía ¿cómo me lo podría explicar? ¿Qué nos hace pensar el mensaje que nos está diciendo Josué?

La situación demanda la necesidad de aclarar una idea: hay un mensaje que aportó un niño y que parece necesitar explicación. Otro pequeño adelanta un juicio ético sobre la frase que dijo el anterior:

- Reidel: Oh... eso es una mala palabra.

-Maestra: Que es una mala palabra, dice Reidel. Alexander ¿a vos te parece que es una mala palabra? -Alexander: No, yo pienso que es feo.

-Maestra: Lo que pensás es que es feo y ¿por qué será feo?

En el diálogo se observa una distinción pertinente: el niño que había intervenido para poner en conocimiento de los demás lo que había declarado Josué, ahora hace una diferencia entre que exista una "mala" palabra, un valor negativo o no bueno en la palabra "chinga", y el aspecto estético de la palabra que fue usada. La docente les ayuda a aclarar retomando las palabras del niño:

- Maestra: Es muy feo que nos vean chingos. Ok. Vamos a repetir el mensaje de nuevo. Josué dijo que lo veía chingo, ¿era así?

Pero su intento es corregido por un niño que subraya y aclara de lo que se trata:

—\#: No, que pensó en una chinga.

Maestra: Ah, qué pensó en una chinga, entonces esa chinga ¿qué quiere decir?

Y, por fin, una niña, detecta la ambigüedad y explica a qué se refería Josué con la palabra asociada a la figura que aparece en la portada del libro Hospital de Muñecos:

-@: Es una muñeca sin ropa.

-Maestra: Qué es una muñeca sin ropa... ¿qué más podemos pensar?

La maestra orienta a la comunidad de diálogo cuando asocia los términos "feo" y "vergüenza" al reproducir la oración de Josué "es muy feo que nos vean chingos": el tema que introdujeron los niños resultó de mucho provecho puesto que de modo natural y abierto ingresan al tema de la desnudez con la lectura que hacen de la portada de la novela. Las inquietudes sobre el propio cuerpo se aplican al caso de la muñeca. Así justifican: "es una muñeca sin ropa" y "no una persona sin ropa". Las participaciones del grupo ejercitan dos tipos de pensamiento filosófico: pensamiento ético (¿será bueno o malo el que nos vean sin ropa?) y estético (¿será feo o bonito?).

Y así la docente fomenta habilidades de pensamiento en los niños, creando alternativas para la solución de un problema. Igualmente, los niños crean alternativas en búsqueda de posibles soluciones. La CdD no se conforma con una única solución sino que aporta más de una respuesta ante un problema.

- Maestra: Oigan que interesante. Jimena está diciendo que para que la muñeca no esté chinga hay que ponerle ropa. ¿Esa podría ser una solución?

-Alexander: Hay que ponerle ropa. Si no tuviera ropa para bebés eso sí sería una misión imposible.

En este caso el grupo muestra ser capaz de proponer ideas sobre cierta relación entre el tamaño proporcional entre la ropa y quien la lleva, lo cual induce cierta reflexión para prevenir o planificar acciones y resolver situaciones.

La docente con sus preguntas, posibilita que emerjan algunos criterios que al ser verbalizados permiten al grupo pensar como comunidad de diálogo, a partir de las ideas y de las afirmaciones de los demás. De esta forma, las habilidades de pensamiento ayudan a las capacidades de convivencia: esto es vital para fundar una comunidad de diálogo.

El enfoque en la temática se observa, tal y como lo afirma la docente "A pesar de que no haya un orden de estar levantando la mano, no se pierde el hilo de la conversación, ya que los estudiantes retoman el tema", en vista del diálogo como elemento dinamizador en una comunidad de aprendizajes.

A la sesión tercera se le llamó "La sorpresa de los nombres”, en esta sesión la docente siguió las recomendaciones que le hizo el grupo de investigación en la sesión anterior, por lo que esta sesión fue dedicada al tema de "los nombres", ella leyó el siguiente párrafo: "Mi muñeca se llama Frida. Ese el nombre 
que yo le puse. Cuando me la dieron no tenía nombre. Cuando yo nací tampoco tenía nombre." (Sharp, 2004, p. 2)

Este fragmento permitió a los estudiantes externar su preocupación con respecto a una posible confusión de las mamás esperando a sus hijos al final de la jornada pedagógica.

-Alexander: yo un día me confundí...

-Maestra: ¿un día te confundiste?, y ¿cómo resolviste el problema?

-Alexander: no sé, viendo las caras.

La evidencia de que sí les es posible confundirse de mamá estriba en que "un día se confundió", pero el planteamiento del problema es que uno reconoce a las personas "viéndoles la cara", y ¿cómo resolver esa necesidad cuando el tamaño del niño impide ver -en una muchedumbre- el rostro de su madre?: según la ayuda que da la docente, se consigue formular la pregunta apropiada para este momento. Literalmente, las mamás se distinguen por los rostros, ¿qué hacer cuando no se le puede ver el rostro y uno la necesita? La reflexión va abriendo la posibilidad de encontrar mundos posibles en medio de formas de pensar sobre un problema tan sensible.

La CdD, en esta sesión estuvo muy interesada en las confusiones de los nombres; para finalizar, un niño establece una dificultad que podría explicar la complicación máxima que originaría todas las confusiones:

—@: Pero hay mamás iguales

Maestra: ¿Y cómo hay mamás iguales?, ¿nacen así, iguales?, ¿las mamás que vienen aquí a recogerlos a ustedes son iguales?

Varios: ¡No!

Maestra: ¿Solo si fueran gemelas iguales, verdad?

Alexander: ¡Ah ya sé cómo uno se confunde, como que dos mamás fueran gemelas y lo llaman Abigail, entonces uno se confunde!

En la tradición filosófica occidental, este razonamiento "al absurdo" ha sido muy importante para imaginar hasta qué punto extremo podría llevarse la discusión y tratar de fijarle parámetros epistemológicos mínimos.
El razonamiento ("hay confusiones que sí se pueden dar”), como confundirse de mamá, porque dos de ellas sean gemelas idénticas, da razón, a quien expuso el caso, de estar legítimamente confundido aún cuando parezca extraordinario por tratarse de la propia mamá; en conclusión: cualquiera podría reírse porque suena "ridículo" pero es cierto. El tono de "vacilón" que asumió el grupo al inicio de esta sesión filosófica, no era el de "seriedad" con el que finalizó la sesión número tres.

En esta sesión, la CdD demuestra que el tema de los nombres es "un verdadero tema filosófico", y la maestra concuerda en esto, porque permite abordar varios argumentos que giran alrededor de él. Es aquí donde la labor del docente en FpN es fundamental, porque es él quien va guiando la conversación y quién permite la posibilidad de hablar del asunto y de realizar las interrogantes "propias" para los intereses de los niños; ahondar más en el tema y "medir también el interés de los niños en ciertos temas". Como menciona Santiago (2002) "una de las maneras más usuales de ejercitar las habilidades de pensamiento consiste en ponerlas en juego a través de preguntas que formula el docente" (pág. 60). En la experiencia narrada podemos señalar que la agenda temática fue cuidadosamente seleccionada por la maestra y el grupo de investigación, conforme el ritmo de intereses del grupo de niños.

En las conversaciones pedagógicas, desarrolladas posteriormente a cada sesión, se le recomendó a la maestra, debido a la cantidad de personas, colocar a la comunidad de diálogo en subgrupos, para poder trabajar más temas de interés del grupo.

Asimismo, un punto de la metodología de FpN en el que se hizo especial énfasis reside en la importancia de "la escucha" entre compañeros, regulada por las ideas de los párrafos leídos en la novela del día.

La cuarta sesión fue denominada "Dejemos volar la imaginación” y en ella se conversó acerca de varios temas que surgieron de las primeras intervenciones infantiles, inmediatamente después de escuchada la lectura: ¿cómo ocurrió el hecho de que se perdió un muñeco?, ¿por qué va al hospital de muñecos?, ¿por qué se escapó?, ¿cómo lo atropellaron?, 
¿por qué va tantas veces al hospital? Un problema filosófico extraído para la discusión fue: si los peluches no pueden caminar, entonces ¿cómo hizo para llegar al hospital?, ¿por qué siempre lo tienen que atropellar?, ¿qué significa que le hicieron un poder? ¿Quiénes tienen poderes? ¿Por qué Patrick se vistió de muñeco de peluche?

Ahora bien, parte importante de la FpN, es la producción de preguntas por parte de los niños, además del papel de la maestra para facilitar la sesión, de forma que se pueda indagar a raíz de la aclaración, desarrollo y profundización de las preguntas. Debe rastrearse lo que más les interesó del tema en discusión, buscando "buenas razones" de algunos problemas filosóficos que enriquecen el conocimiento individual y grupal.

En esta sesión, la docente, rápidamente, vistió a uno de los niños como un gran oso rosado, por lo que conversar con un muñeco grande y rosado, fue para los niños una gran experiencia, esta dinámica fue un gran acierto de la maestra, porque logró que los niños mantuvieran el interés en el tema y, continuarán sus diálogos, con un muñeco real.

Durante el diálogo de los niños, se hacen conexiones entre el niño y el muñeco, además se dan explicaciones para hacer entender que el muñeco se parece a uno de sus compañeros pero que ahora tiene un disfraz. Se nota, además, capacidades de convivencia, como por ejemplo hacer silencio para poder escuchar a los participantes.

Es preciso destacar, que las diferentes actividades que la docente planea para el desarrollo de la clase de filosofía, demuestran el interés por crear un ambiente propicio para dialogar y que a su vez se desarrollen habilidades del pensamiento y capacidades de convivencia.

En la conversación pedagógica se reflexionó acerca de la gran transformación, la docente inicia el trabajo de FpN con grupos pequeños de trabajo, lo que permite invitar a los niños a pensar, a conversar y hacer preguntas con más facilidad. Es evidente que es más enriquecedora esta manera de trabajo; la maestra, al dedicar cierto tiempo a cada grupo, crea espacios de reflexión sobre el tema en cuestión.
Por otro lado, la creatividad de la docente se hizo evidente, el transformar a un niño en un muñeco de verdad, no solo fue novedoso para los investigadores, sino que además los niños disfrutaron mucho, lo que crea cierta identificación por parte de una comunidad tan pequeña con un tema tan importante, como es filosofar.

En la quinta sesión de este trabajo, el tema fue "No me interesa, solo quiero jugar", la lectura fue anunciada y se formó un gran círculo, el grupo escuchó con atención:

\begin{abstract}
"Cuando es hora de sentarnos en círculo todos sabemos que la maestra nos va a leer una historia y luego nos va a hablar sobre esa historia.

Hay reglas para hablar cuando estamos sentados en círculo. La maestra nos ayudó a averiguar cuáles eran esas reglas y luego las escribió.

Tomamos tiempo para hablar, tratamos de escuchar con cuidado lo que cada uno dice. Decir porque lo pensamos, cuando a alguien le cuesta trabajo dar una razón, todos le ayudamos". (Sharp, 2004, p.13)
\end{abstract}

Consideramos que, en esta sesión, las respuestas fueron más allá de lo que esperaba la facilitadora. La fantasía se ha introducido, en cierta forma, en sus conversaciones, elemento fundamental, pues "sin la fantasía es imposible el desarrollo del pensamiento científico, artístico y filosófico" (Burgos y Delgadillo 2003 p. 8).

Maestra: Muy bien, Gabriel. Alexander, ¿usted puede pasar adelante y contarnos de qué hablaron en tu grupo?

Alexander: Nos contamos los sueños que habíamos soñado.

Maestra: ¿Hablaron de los sueños? ¿Y de la historia de hoy, tendrá que hablar de los sueños?

Alexander: No.

Maestra: No, ¿con qué tendría que ver?

Alexander: Conversar.

Maestra: ¿Conversar de qué?

Alexander: De que estábamos en el cielo.

La referencia al cielo que hacen los niños resulta ser un concepto religioso, y se destaca su imagen de las "regiones celestes" al considerarlas un lugar divertido; su interés les lleva a concluir que en 
ese lugar "pueden hacer lo que les encanta, jugar". También pueden considerar el cielo como el lugar que nadie sabe dónde está pero una forma de llegar a él es por medio de los sueños. La docente también se siente encantada con el tema de los sueños que estos niños plantean ante su cuestionamiento.

Otra temática dialogada en otros subgrupos:

Maestra: A ver, Alexandra ¿usted sería tan amable de contarnos de qué hablaron, qué pensaron?

Alexandra: De lo que íbamos a ser cuando grandes. Maestra: Ajá... y ¿qué resultó de esa conversación?

Alexandra: De que yo quería ser una veterinaria y ellas dijeron de lo que querían ser y Isabela dijo que ella quería ser una astronauta.

Maestra: ¿Y qué pensás acerca de ser una astronauta? Alexandra: Que eso es peligroso.

Maestra: Que es peligroso, ok.

Las expresiones orales de los niños en esta sesión resultan ser frases muy cortas, lo cual limita la interacción dialógica. Esto no significa que no se esté dando el desarrollo de habilidades cognitivas en los niños, porque ellos permanecen reflexionando y "la reflexión es una actividad permanente, ligada, por lo general, a los problemas de su tiempo" (Burgos y Delgadillo 2003 p. 10).

Se puede observar que la docente utiliza la fórmula de pregunta: ¿qué piensan de..?, este protocolo de intervención es una forma de invitarles a que hagan un juicio, según Sharp y Splitter (2004 p.16) "Uno de los propósitos de hacer filosofía con los niños pequeños es ayudarlos a hacer mejores juicios"; en otras palabras, ayudarlos a que logren expresar sus opiniones, a la vez brindando buenas razones $y$, al repensar los argumentos, puede ser que cambien o confirmen sus puntos de vista iniciales.

La sesión sexta tuvo como nombre ¿Qué hay en la mente? La docente inició proponiéndoles a los estudiantes trabajar en un tema libre; a la luz de la propuesta una estudiante le responde que "no sabe”, ingeniosamente la docente pregunta: ...¿qué significa eso?, luego de varias hipótesis una niña le contesta "que no tiene ninguna palabra en la mente -", al respecto, la docente dice "perfecto", dando a entender que es una respuesta de gran valor, para luego profundizar sobre si "eso" (no tener nada en la mente) sería posible. Al respecto, Santiago (2000) menciona que "lo importante es tener presente que, si no queremos que la clase se quede en un espacio de expresión cuyo interés sea cada vez menor, debemos poner nuestro empeño para que la discusión avance" (p. 59).

Cuando se desarrolló esta temática se acercaba la época navideña; la CdD tenía especial interés en el tema, por lo que no sorprendió a nadie la interrogante siguiente:
@: Niña ¿para qué se hace la Navidad?
Maestra: muy bien ¿por qué?
@: Se inventó la navidad porque ahí fue el nacimien- to de Dios.
Maestra: Sí, “ ¿por qué más se hace la Navidad?
Xiomara: Porque ahí se celebra con toda la familia.
Maestra: Sería como una actividad para celebrar en familia. ¿Qué más se les ocurre pensar de la Navidad? Dijeron que es un momento para estar en familia, que se celebra el nacimiento de Dios.
@: De Jesús.
Maestra: Sí, de Jesús. ¿Será un momento bonito, será un momento aburrido, será un momento que no nos gusta?
\#: Es lindo porque nos traen regalos.

En este fragmento se rescatan dos aspectos valiosos en cuanto a las capacidades de convivencia: primero, vemos que el diálogo inicia con una pregunta formulada por una niña, que sintió la confianza de manifestar una duda, a raíz de una fecha que se aproximaba y cuya celebración es significativa para el grupo.

El segundo aspecto es que a pesar de que esta primera pregunta es dirigida a la maestra, una niña se adelanta y responde, pautándose una interacción propia de "pares", lo que en FpN es muy valorado porque se evidencia que los niños empiezan a mostrar confianza entre sí: nos queda claro que al contestar otra niña, ella está atenta a las dudas de su compañera y sintió la confianza de responder ante un tema del que tenía conocimientos que quería compartir: en Navidad se celebra familiarmente. Menciona Velasco (2002) que "si los estudiantes observan y piensan juntos sobre un mismo problema, necesitan escucharse con atención unos a otros 
y entonces surgirá una gran riqueza en las posibles explicaciones que se dan respecto a un tema" (p. 4).

Podemos denotar como los niños se van comunicando con menos mediación de la docente, esto hizo al grupo de investigación preguntarse, a qué podría obedecer esto: ¿van mejorando las habilidades de convivencia? ¿Es el tema que mencionó el niño que era de interés de otros? Lo que vemos relevante es la importancia de la relación que se produce entre las habilidades de pensamiento y las capacidades de convivencia: ¿hay evidencia de que, en este grupo de niños, "pensar y convivir", está pasando a constituir una unidad profunda o sólo lo parece?

Siguiendo con las conversaciones pedagógicas del grupo de investigación, se comentó que el trabajo en sub-grupos, permite un mejor manejo por parte de la docente; al trabajar con el grupo en general los niños tienen que esperar más para intervenir por turnos como lo dicta la CdD. También se evaluó que el tema libre le permitió a la CdD expresar mejor sus intereses y necesidades; por ejemplo, sacando a reducir lo de la Navidad.

Se recomienda así trabajar en sub-grupos, ya sea que se proceda a leerles un párrafo de la novela ("Hospital de Muñecos" u otra), o a proponer un tema de libre conversación.

Si se preguntara a un adulto qué significa "el juego" podría dar muchas opiniones válidas, en el caso de los niños, nos interesó la dimensión lúdica como medio para la construcción de conocimiento. La sesión sétima, desarrolla este tema.

Para abrir el diálogo con los niños, la docente decide trabajar nuevamente en grupos (de entre $6 \mathrm{u}$ 8 niños) e inicia con la siguiente lectura, tomada de Hospital de Muñecos:

"Cuando llegué a la guardería llevaba a Frida en mis brazos. Por un momento me quedé parada frente a la puerta viendo cómo jugaban los otros niños. Algunos niños estaban trabajando con sus libros de colorear. Francisca y Carlota jugaban a la comidita en una de las mesitas en donde tomamos el refrigerio. Ramona y Jaime estaban jugando con las muñequitas de la casa de muñecas. Gabriela y Lupe jugaban con los Legos"
Conforme la sesión se fue desarrollando, se percibe en los comentarios un tema derivado pero igualmente inesperado: las fechas anuncian que pronto los niños del preescolar dejarán las aulas del Kínder. En su diálogo expresan sentimientos de tristeza, sensibilidades profundas sobre las expectativas que genera este cambio que se avecina; pronto irán a la escuela y dejarán de ir al Kínder y para ellos eso significa "dejar de jugar", la frase es lapidaria: "en la escuela no se juega, solo se estudia y se tienen que poner las pilas".

Lo anterior, se relaciona con lo que expresa Echeverría (2004), referente a la sensibilidad del contexto como una característica de la dimensión del pensamiento crítico que entraña la FpN: para el filósofo mexicano, a su vez, el pensamiento crítico permite desarrollar la capacidad de realizar inferencias. La deliberación supone la calidad y lo pertinente o no de esas inferencias.

En el aula puede percibirse cómo la CdD predice una realidad nueva que proviene de un contexto nuevo (la escuela), hay que reflexionar acerca del mismo y tomar decisiones de cómo actuarán entonces; se oyen sus comentarios:

\#: Y en primero nos tenemos que poner las pilas.

Maestra: Que tienen que ponerse las pilas y ¿qué significa ponerse las pilas?

\#: Que tenemos que hacerlo muy rápido.

@: Y estudiar mucho.

Es importante destacar, que las analogías proporcionadas por los niños, (tomadas del contexto familiar o escolar), durante sus intervenciones, son ejemplo de una búsqueda de fundamentación de esa nueva situación; sus comentarios, ante la comunidad de diálogo, indagan porque interesa lo que otros saben al respecto.

Maestra: ¿Qué más diferencias hay en la escuela? ¿Porque me están hablando de cosas diferentes?, pero aquí nos estaba presentando que cuando llegó a la escuela jugaba y ustedes me están diciendo que el juego es diferente.

@: Ah ya, vienen y van al play como los que hay en la escuela.

Maestra: ¿que más nos hace pensar?....ah Sebastián 
Sebastián: Que hay que estudiar mucho. Maestra: Que hay que estudiar mucho.

\#: Y en primero nos tenemos que poner las pilas.

Como se ha logrado visualizar en la dinámica del trabajo con los niños, una de las mejores formas de inducir a los participantes a comentar sobre sus ideas, es por medio de "preguntas". En todas las sesiones de trabajo, este fue el mejor de los medios para dar inicio a la comunidad de diálogo. En su mayoría, la pregunta era pensada por la docente, no obstante, conforme los niños se iban apoderando de la filosofía, realizaban preguntas que ponían a todos a pensar y que a su vez motivaban hablar. Visualizando el cambio hacia la escuela, los niños piensan que hay que estudiar mucho, los comentarios permiten entender que ellos pueden entender claramente que la escuela es diferente al Kínder, al decir "tenemos que ponernos las pilas": es la mejor explicación que pueden hallar ante una realidad inminente que están por venir. Esto nos hace reflexionar en lo siguiente: ¿el ambiente escolar -su organización-permite o limita los espacios para el aprendizaje, en el caso de niños que pasan de kínder al primer grado escolar?

La docente, al finalizar esta sesión, decidió realizar una evaluación a la clase de Filosofía. La Filosofía para Niños, mediante la comunidad de diálogo, abre espacios para que se modelen valores que a su vez desarrollen capacidades de convivencia. El espacio de evaluación, que la docente abrió para conocer si a los niños les gustó o no la clase de Filosofía, suministra insumos que indican el desarrollo de estas capacidades, como por ejemplo:

- $\quad$ Porque hay que estar calladito.

- Y no hay que estar inquietos.

- Y no hay que movernos.

Si la Filosofía para Niños, permite que los individuos no solo aprendan a razonar, a pensar, sino que además beneficia a las relaciones interpersonales, ¿cómo continuar desarrollando experiencias de FpN en las aulas costarricenses?

En la conversación pedagógica de investigadores se reflexionó acerca de que la sesión de Filosofía para Niños es más provechosa cuando se trabaja en grupos de 6 niños, a lo sumo. Debido, principalmente, a que permite que los niños mantengan el interés en la temática desarrollada, ya que pueden preguntar por lo que escucharon y opinar sobre lo que creen o piensan. Otro aspecto importante es que los pequeños grupos facilitan el que los niños sean más conscientes de las capacidades de convivencia, y capten y expresen en sus diálogos que para escuchar, hay que hacer silencio (estar calladitos).

La docente considera "que la propuesta de $F p N$, es un medio que renueva la práctica pedagógica, transforma la rutina de trabajo, no obstante es consciente que para aplicarla es necesario conocer la metodología de trabajo, para dirigir a la comunidad hacia el cuestionamiento, que por medio de preguntas y respuestas, forma infantes críticos, que con sus comentarios fundamentan sus propias respuestas".

\section{CONCLUSIONES}

La Filosofía para niños plantea problemas a una Comunidad de Diálogo teniendo en cuenta que éstos sean de naturaleza filosófica, esto significa que no todo problema escolar lo es, y, más centralmente, se trata de un asunto que demanda razonamientos y argumentos intrínsecos a su descripción y comprensión. El carácter filosófico puede implicar valoraciones sobre "justicia" en las relaciones humanas (problema ético), indagaciones acerca del rango de verdad o falsedad que entraña una afirmación (problema lógico) o deliberaciones entorno del carácter "bello o feo" de algún fenómeno o experiencia (problema estético).

No todo tiene el mismo parámetro de abordaje porque la naturaleza de cada uno de estos niveles de análisis (ético / lógico / estético) requiere enfrentamientos distintos de las problemáticas convocadas; por eso, el desafío en FpN se ofrece como una oportunidad de encuentro y desencuentro entre personas que -al fin y al cabo- son quienes entran en debate. Para que puedan expresar sus opiniones sin ser recriminadas, necesitan un mínimo de reglas que mantenga en orden la discusión.

Desde el punto de vista emocional, se puede considerar como un medio de refuerzo para que los niños que presentan timidez, comiencen a superar 
esta condición y puedan, a su vez, expresar sus opiniones sin sentirse amenazados.

La propuesta metodológica de $\mathrm{FpN}$ es un recurso muy viable para aplicar en el aula preescolar; colabora en el desarrollo no solo de habilidades comunicativas, sino en la formación de personas más humanas, autorreguladoras, críticas, objetivas, coherentes en su discurso.

Se debe establecer un perfil del maestro de $\mathrm{FpN}$, en el cual ha de considerarse deseable su creatividad $y$, flexibilidad, el que sea un maestro con empoderamiento de FpN, dinámico, crítico, observador, conciliador, empático, ordenado, con valores humanos, de forma que, con su conocimiento, pueda actuar en el desarrollo de una verdadera $\mathrm{CdD}$ en la sala de clase de preescolar.

La familia debe ser involucrada en el trabajo de FpN, conocer la dinámica del mismo y los roles de la maestra y los niños, con lo que se refuerza el logro de sus objetivos.

Un proyecto de Filosofía para Niños, debe iniciar una vez que el grupo preescolar haya logrado un proceso de adaptación a la dinámica del jardín, para que así la comunidad de diálogo pueda obtener mayores beneficios en lo que al desarrollo de habilidades de cognitivas y de convivencia se refiere.

Los niños del grupo han demostrado su pensamiento ético y creativo, se observa en sus intercambios sobre aspectos de bueno o malo y de bonito ofeo.

Los niños del grupo demostraron sus habilidades de pensamiento al plantear preguntas, establece comparaciones, construir definiciones, clasificar en categorías y argumentar sus respuestas.

La comunidad de diálogo utiliza el lenguaje lúdico, pues se percibe el disfrute del mismo al aportar expresiones como... "una misión imposible", "ponerse las pilas" las cuales no se les conocieron en su lenguaje cotidiano. Cada vez que se presenta la oportunidad, los niños aprovechan para jugar con el lenguaje.

Otro aspecto que se concluye es una incipiente meta cognición y, esto ocurre en la dinámica constante donde la docente estimula el pensamiento por medio de la pregunta filosófica.

La maestra representa un modelo para la formación de buenos modales en los niños, quienes reciben sus palabras gentiles y respetuosas, situación que de acuerdo con Sharp constituye un contenido, de $\mathrm{FpN}$, a desarrollar con los más pequeños.

Como parte del componente creativo y estético que propone $\mathrm{FpN}$, la docente puede desarrollar, como parte de las sesiones con la novela Hospital de los Muñecos, actividades como las siguientes:

- Ambienta, en la sala de clase, un espacio para que la doctora de consulta a los muñecos que el grupo aporte, porque consideren que necesitan ser atendidos. Cada niño planteará la situación particular del "paciente" y será la doctora quien ayude a "sanar" dicha necesidad. La doctora llevará en su maletín elementos para atender a los muñecos: hilo, aguja, cinta adhesiva, pegamentos, etc. Esta actividad puede favorecer en el grupo la formación de imágenes, y aportar otro tipo de experiencias previas a la lectura de los párrafos de la novela Hospital de Muñecos.

- Elaboración de muñecos de diferente material: tusa de elote, papel, cartulina, fieltro, tela, espuma, galletas, plastilina, gelatina, madera de balsa. La vestimenta de los mismos puede realizarse de acuerdo con el material que "compagine".

- Elaboración de "muñecos títeres" de mano, de dedo, de mesa y marionetas que puedan permanecer en la sala de clase con fines lúdico-pedagógicos.

Finalmente, el presente artículo -como quedó señalado atrás- describió el proceso de aprendizajes obtenidos según la narración de la experiencia: quedará para otro artículo la sistematización de elementos más reflexivos, provenientes de la teoría de los contenidos filosóficos de FpN, a la luz de obras de Lipman, de Ann Sharp y de otras personas que han realizado un trabajo en este campo, en la región latinoamericana, como Eugenio Echeverría en México, Stella Acorinti en Argentina y Kattya Arroyo en Costa Rica. 


\section{REFERENCIAS}

Acorinti, S. (2000). LIS. Buenos Aires: Manantial.

Acorinti, S. (2000). Maravillándome con mi experiencia. Material de apoyo para acompañar a LIS. Buenos Aires: Manantial.

Acorinti, S. (2000). Trabajando en el aula. Buenos Aires: Manantial.

Barrantes, R. (1999). Investigación: un camino al conocimiento, un enfoque cualitativo y cuantitativo. San José: EUNED.

Bisquerra, R., \& Sabariego, M. (2004). Proceso de Investigación (parte1). En R. Bisquerra, Metodología de la Investigación Educativa. (págs. 89-125). Madrid: La Muralla.

Cervantes, M. y otros. (2007). Desarrollo de las destrezas del pensamiento mediante el método de Filosofía para Niños, en los grupos de transición de los CENCINAI de Moravia, Sabanilla y Vargas Araya. Tesis para optar por el grado de Licenciatura en Educación Preescolar. San José: Universidad de Costa Rica.

Echeverría, E. (2004). Filosofía para niños. Mexico D.F: Santa María.

García, F. (1998). Crecimiento moral y Filosofía para niños. Bilbao: Desclée de Brouwer.

Gutiérrez, F. (2002). Simiente de Primavera. Protagonismo de la niñez y la juventud. PRODESSA.
Hernández, R., Fernández, C., \& Baptista, P. (2003). Metodología de la Investigación. Mexico: Mc Graw Hill.

Latorre, A. (2004). La Investigación Acción. En R. Bisquerra, Metodología de la Investigación Educativa (págs. 369-394). Madrid: La Muralla.

Lipman, M. (2003). Pixi. Buenos Aires: Novedades Educativas.

Ministerio de Educación Pública. (1998). Programa de Educación preescolar. San José, Costa Rica.

Sabariego, M. (2004). El proceso de investigación (parte 2). En R. Bisquerra, Metodología de la Investigación Educativa (págs. 127-163). Madrid: La Muralla.

Santiago, G. (2002). Filosofía con los más pequeños, fundamentos y experiencias. Buenos Aires: Novedades educativas.

Sharp, A. (2004). Hospital de muñecos. Chiapas, Mexico: Fray Bartolomé de Las Casas.

Sharp, A. y Splitter L. (2004) Hospital de los muñecos. Manual. Chiapas, México: Fray Bartolomé de Las Casas.

Trejos, V.( 2007). Instituto de Investigación en Educación de la Universidad de Costa Rica. Recuperado. Recuperado noviembre 2010. www.inie.ucr.ac.cr/encuentro/memoria/experiencias/virginia.pdf

Velasco, M. (2002). El arte de pensar bien. Módulo Introductorio. Mexico: CEFILNI. 
